\title{
Genetic variation of genes for xenobiotic-metabolizing enzymes and risk of bronchial asthma: the importance of gene-gene and gene-environment interactions for disease susceptibility
}

\begin{abstract}
Alexey V Polonikov, Vladimir P Ivanov and Maria A Solodilova
The aim of our pilot study was to evaluate the contribution of genes for xenobiotic-metabolizing enzymes (XMEs) for the development of bronchial asthma. We have genotyped 25 polymorphic variants of 18 key XME genes in 429 Russians, including 215 asthmatics and 214 healthy controls by a polymerase chain reaction, followed by restriction fragment length polymorphism analyses. We found for the first time significant associations of CYP1B1 V432L $(P=0.045), P O N 1 Q 192 R(P=0.039)$ and UGT1A6 T181A $(P=0.025)$ gene polymorphisms with asthma susceptibility. Significant $P$-values were evaluated through Monte-Carlo simulations. The multifactor-dimensionality reduction method has obtained the best three-locus model for gene-gene interactions between three loci, EPHX1 Y113H, CYP1B1 V432L and CYP2D6 G1934A, in asthma at a maximum cross-validation consistency of $100 \%(P=0.05)$ and a minimum prediction error of $37.8 \%$. We revealed statistically significant gene-environment interactions (XME genotypes-smoking interactions) responsible for asthma susceptibility for seven XME genes. A specific pattern of gametic correlations between alleles of XME genes was found in asthmatics in comparison with healthy individuals. The study results point to the potential relevance of toxicogenomic mechanisms of bronchial asthma in the modern world, and may thereby provide a novel direction in the genetic research of the respiratory disease in the future. Journal of Human Genetics (2009) 54, 440-449; doi:10.1038/jhg.2009.58; published online 3 July 2009
\end{abstract}

Keywords: bronchial asthma; gene-environment interactions; gene-gene interactions; genetic predisposition to disease; single-nucleotide polymorphism; xenobiotic-metabolizing enzymes

\section{INTRODUCTION}

It is generally agreed that bronchial asthma is a multifactorial disease, the phenotypic manifestation of which depends on a complex interplay between multiple genes of small-to-modest effect and on a number of environmental factors. ${ }^{1,2}$ Although numerous genetic association studies and genome-wide linkage scans have identified more than 100 potential susceptibility genes contributing to asthma over the past few decades, ${ }^{1-5}$ we still poorly understand which genetic and environmental factors should be considered as major causes of asthma in the modern world. In particular, it is unclear whether known candidate genes of asthma susceptibility explain a sharp increase in the prevalence of asthma worldwide in the last few decades. ${ }^{6}$ It has been proposed that an increase in the incidence of asthma, projected against a relatively unchanged human genome in evolutional sense, can be attributed to gene-environment interactions rather than to genetic factors itself to determine the predisposition to the disease. ${ }^{7}$ This means that the asthma epidemic in the world cannot be simply explained by known genetic factors. After many years of research, a small number of environmental factors have been shown without doubt to cause bronchial asthma in the general population. Among them, particulate air pollution, which has progressively increased in the last few decades, seems to be a quite plausible candidate as a major environmental determinant of asthma, as the increased incidence of asthma has been found to be strongly associated with exposure to particulate matter of the environment in many countries. $^{8-11}$ Moreover, air pollutants, such as particles, diesel exhaust, polycyclic aromatic hydrocarbons (PAHs), ozone, oxides of nitrogen, sulfur dioxide etc, have been shown to induce oxidative stress that was found to have an essential role in allergic inflammation, increasing airway responsiveness and inducing acute asthma exacerbations. ${ }^{8,10,12}$ Several genetic studies have observed that individuals possessing loss-of-function variants of genes for glutathione $S$-transferases (antioxidant enzymes) are more susceptible to adjuvant effects of airborne pollutants increasing the risk of bronchial asthma. ${ }^{13,14} \mathrm{We}$ have recently confirmed that some other antioxidant genes are also proper candidates for asthma susceptibility genes. ${ }^{15-18}$ However, 
a little research has been conducted to investigate the impact of highly variable polymorphic genes for xenobiotic-metabolizing enzymes (XMEs) on the development of bronchial asthma. It is well known that XMEs in various types of cells in the human lung and airways contribute to the in situ activation and inactivation of many chemical toxicants of the environment. ${ }^{19}$ Thus, tissues of the respiratory tract, which are exposed to both inhaled and blood-borne xenobiotic compounds, are important targets for environmental toxicity. Therefore, it would be reasonable to propose that considerable interindividual differences in the expression and/or activity of XME genes may contribute substantially to asthma susceptibility. However, despite a clear importance of ecological genetic research of asthma etiology, existing data on the impact of genetic polymorphisms of XME genes on the development of asthma are still surprisingly limited. Thus, the purpose of our pilot study is to investigate whether polymorphic genes encoding XMEs, which metabolize major classes of chemicals of the environment, represent a valuable genetic component of susceptibility to bronchial asthma. Taking a polygenic multifactorial nature of asthma into account, it was also important to investigate gene-gene and gene-environment interactions contributing to disease susceptibility.

\section{MATERIALS AND METHODS}

\section{Selection of candidate genes}

We have selected genes for XMEs and their genetic variants from available publications and public databases in accordance with the following criteria: (1) the enzymes should represent all phases of biotransformation of xenobiotics, that is, typical phase I, II and III enzymes (biological functions and genetic variation of the enzymes are summarized in Supplementary Table 1); (2) the enzymes should metabolize major classes of chemicals of the environment (data on the roles of XMEs in the metabolism of environmental chemicals are summarized in Supplementary Table 2); (3) the enzymes are expressed in the lung and/or airways; (4) single-nucleotide polymorphisms (SNPs) of XME genes should be functionally significant, whenever possible; and (5) the minor allele frequency for XME genes should not be $<5 \%$.

\section{Study population and diagnosis of asthma}

A total of 429 unrelated participants were recruited into the study, including 215 patients with doctor-diagnosed bronchial asthma and 214 age- and sexmatched healthy individuals. Demographic characteristics of study groups are shown in Table 1. The mean age of the asthmatics was 43.3 years ( 94 men and 121 women), and the mean age of healthy individuals was 41.3 years ( 105 men and 109 women). All patients were recruited from the Division of Pulmonology at the Kursk Regional Clinical Hospital over a period from 2003 to 2004. The healthy individuals were recruited at the same time. The diagnosis of asthma was verified by the presence of characteristic symptoms, reversibility of airway obstruction (15\% variability in forced expiratory volume per second or in peak expiratory flow rate, either spontaneously or with an inhaled short-acting $\beta 2$ agonist) or airway hyperresponsiveness to methacholine (a result of a challenge with a provocative concentration of methacholine causing a $20 \%$ decrease in $\mathrm{FEV}_{1}$ of $\left.<8 \mathrm{mg} \mathrm{m}^{-1}\right)$. Skin prick testing and total serum immunoglobulin $\mathrm{E}$ (IgE) levels were determined in all study participants. The healthy individuals for the control group were enrolled in accordance with the following criteria: (1) no symptoms and history of allergic and/or other chronic diseases; (2) normal total serum IgE levels; and (3) normal pulmonary function test results. All patients and controls were of Russian origin from Central Russia. All study participants completed an interviewer-administered questionnaire with regard to cigarette smoking habits (ever/never smokers) and demographic data. Data on smoking status were available from 194 asthmatics and 167 healthy individuals (Table 1). A strong positive history of asthma was shown in cases (40.1\%) in comparison with controls $(6.7 \%)$. This study was carried out according to the principles of the Declaration of Helsinki, and written informed consent was obtained from each participant after a detailed explanation of the aim of the study. The study protocol was approved by the Ethical Review Committee of the Kursk State Medical University.

\section{Genotyping}

Approximately $5-10 \mathrm{ml}$ of venous blood was collected into EDTA (ethylenediaminetetraacetic acid)-coated tubes from each participant of the study. A genomic DNA was purified from whole blood using a standard procedure, including leukocytes lysis, SDS treatment, proteinase $\mathrm{K}$ digestion, phenolchloroform extraction and ethanol precipitation. All DNA samples were genotyped for 25 SNPs of 18 XME genes by PCR-restriction fragment length polymorphism (RFLP) assays according to the array protocols available from the publications. ${ }^{20-37}$ Supplementary Table 3 shows SNPs that have been analyzed in the study. PCR was performed in a final volume equal to $25 \mu \mathrm{l}$ of reaction mixture containing $1.5 \mathrm{U}$ of thermostable Taq DNA polymerase (Lytech, Moscow, Russia), $\sim 1 \mu \mathrm{g}$ DNA, $0.25 \mu \mathrm{M}$ of each primer, $250 \mu \mathrm{M}$ of dNTPs, $1.5-3.5 \mathrm{~mm}$ of $\mathrm{MgCl}_{2}$ and $1 \times$ PCR buffer $(67 \mathrm{~mm}$ Tris- $\mathrm{HCl} \mathrm{pH} 8.8$, $16.6 \mathrm{~mm}\left(\mathrm{NH}_{4}\right)_{2} \mathrm{SO}_{4}, 0.01 \%$ Tween-20). The PCR products were digested by respective endonucleases (Sibenzyme, Novosibirsk, Russia) using the buffers recommended by the manufacturer. A negative (water) and a positive control for the respective gene polymorphism were used in each RFLP assay. The restriction digest products were analyzed through 2-3\% agarose gel electrophoresis containing ethidium bromide and visualized under ultraviolet light on the GDS-8000 Computer Detection System (UVP Inc, Upland, CA, USA). The genotyping results were scored by two independent investigators who did not know whether the sample was obtained from the asthmatic or control group. Random PCR-RFLP retesting of $\sim 10 \%$ of the samples per SNP yielded $100 \%$ reproducibility. In addition, $\sim 10$ randomly selected samples per SNP were sequenced on Genetic Analyzer ABI PRISM 310 (Applied Biosystems; Foster City, CA, USA), and all these genotyping results were concordant with the initial genotyping results.

Table 1 Demographic characteristics of cases and controls

\begin{tabular}{|c|c|c|c|}
\hline Demographic characteristics & Asthmatics n (\%) & Healthy controls n (\%) & P-values \\
\hline Age mean \pm s.d. & $43.3 \pm 11.4$ & $41.3 \pm 10.2$ & 0.06 \\
\hline \multirow[t]{2}{*}{ Gender } & $94 \mathrm{M}(43.7 \%)$ & 105 M (49.1\%) & 0.27 \\
\hline & $121 \mathrm{~F}(56.3 \%)$ & 109 F (50.9\%) & \\
\hline \multirow[t]{2}{*}{ Family history of asthma ${ }^{a}$} & Yes 75 (40.1\%) & Yes 11 (6.7\%) & $<0.00001$ \\
\hline & No 112 (59.9\%) & No 154 (33.3\%) & \\
\hline Body mass index (BMI), $\mathrm{kg} \mathrm{m}^{-2}$ & $23.7 \pm 2.8$ & $22.9 \pm 3.6$ & 0.01 \\
\hline \multirow[t]{2}{*}{ Smoking status ${ }^{\mathrm{b}}$ (ever/never smokers) } & Yes $66(34.0 \%)$ & Yes $66(39.5 \%)$ & 0.28 \\
\hline & No $128(66.0 \%)$ & No 101 (60.5\%) & \\
\hline
\end{tabular}

Abbreviations: $\mathrm{F}$, female; $\mathrm{M}$, male.

aThe family history data were obtained from 187 asthmatics and 165 controls.

bData on smoking status were available from 194 asthmatics and 167 healthy individuals. 


\section{STATISTICAL ANALYSIS}

Statistical power was calculated for a $\chi^{2}$-test on the basis of allele and genotype frequencies for each polymorphism in White populations. We were able to detect a difference of $10 \%$ for a majority of XME genotypes assuming at least $70 \%$ power $(\beta=0.30)$ with a $5 \%$ Type I error rate $(\alpha=0.30)$ and a sample size of 215 patients and 214 controls. Allele frequencies were estimated using the genecounting method, and Hardy-Weinberg equilibrium (HWE) was tested by Pearson's $\chi^{2}$-test. Allele and genotype frequencies between cases and controls were compared using the $\chi^{2}$-test with Yates correction. The strength of the association of XME gene polymorphisms with susceptibility to asthma was estimated by calculating odds ratio (OR) with corresponding $95 \%$ confidence intervals (CIs) using unconditional logistic regression analysis. Multivariate logistic regression was used to assess whether XME gene polymorphisms with other confounding variables such as age and gender may have any significant association with the tested genotypes. A $P$-value of $<0.05$ was set as statistically significant. The statistical calculations were performed using Statistica for Windows (v6.0) software package (StatSoft; Tulsa, OK, USA). Monte-Carlo simulations (CLUMP software, http://www.mds.qmul.ac.uk/statgen/dcurtis.html) were used to evaluate empirical $P$-values $\left(p_{\mathrm{mc}}\right)$ in order to prevent false-positive associations arising because of multiple comparisons between the groups. Gene-environment interactions were evaluated by joint categories of $\mathrm{XME}$ genotypes and smoking status (cigarette smoking was used as a surrogate variable representing a personal exposure to chemicals) with respect to asthma risk. Gene-gene interactions were evaluated by the multifactor-dimensionality reduction (MDR) method implemented into MDR software v.1.1.0 (http:// www.multifactordimensionalityreduction.org). ${ }^{38,39}$ The MDR method is known to be useful in identifying high-order nonlinear or nonadditive genegene interactions in case-control studies with relatively small samples, and in assessing the joint effect of multiple genetic loci on the development of disease. ${ }^{39-42}$ The basis of the MDR method is a constructive induction algorithm that converts two or more variables such as SNPs into a single attribute. MDR reduces the dimensionality of multilocus information to facilitate the identification of polymorphism combinations associated with disease risk. The important advantage of MDR is that the method includes a combined cross-validation/permutation-testing procedure that minimizes false-positive results by multiple examinations of the data. Another advantage is that MDR provides a prediction error, an estimate of the internal validity of the model. The significance of the final MDR model was determined empirically through 1000 permutations using the Monte-Carlo procedure implemented into the MDRpt software (http://sourceforge.net/projects/mdr). The polymorphism G-50T of the CYP2J2 gene was also included in analyses of gene-gene and gene-environment interactions, as we have recently found an association of this polymorphism with asthma susceptibility. ${ }^{43}$ Lewontin's pairwise gametic correlations between alleles of XME genes were evaluated in case and control groups. The estimations were determined by the maximum likelihood method, as described by Hill ${ }^{44}$ from the frequencies of genotypes in the $3 \times 3$ contingency tables under an assumption of the codominance of loci.

\section{RESULTS}

Genotype frequencies for the majority of SNPs were in HWE in cases and controls. A deviation from HWE was noted only for two polymorphisms, $P O N 1 \mathrm{Q} 192 \mathrm{R}$ ( $P=0.03$ in cases, $P=0.05$ in controls) and $E P H X 1 \mathrm{Y} 113 \mathrm{H}(P=0.00001$ in cases, $P=0.05$ in controls). Allele frequencies of 22 SNPs are listed in Table 2. Allele frequencies of GSTM1 and GSTT1-null polymorphisms have not been estimated because we did not genotype heterozygous carriers for these genes. The frequency of variant allele $432 \mathrm{~L}$ of the CYP1B1 gene was higher in healthy individuals than in patients with asthma $(\mathrm{OR}=0.75$, $p_{\mathrm{mc}}=0.041$ ), suggesting a protective effect of the mutation. Genotype frequencies of XME genes are shown in Table 3. CYP1B1 V432L, PON1 Q192R and UGT1A6 T181A gene polymorphisms were significantly associated with risk of asthma. The associations remained significant after an adjustment for age and gender by multiple logistic regression analysis. In particular, genotype 432LL of the CYP1B1 gene was associated with a decreased risk of asthma (adjusted $\mathrm{OR}=0.67$,
95\% CI: $\left.0.44-0.99, p_{\mathrm{mc}}=0.045\right)$. A carriage of variant genotypes of the PON1 gene (192QR plus 192RR) was associated with an increased risk of asthma (adjusted $\mathrm{OR}=1.48,95 \%$ CI: 1.01-2.18, $p_{\mathrm{mc}}=0.039$ ). Genotype 181AA of the UGT1A6 gene was found to be associated with a decreased risk of asthma (adjusted $\mathrm{OR}=0.50$, 95\% CI: $0.28-$ $\left.0.90, p_{\mathrm{mc}}=0.025\right)$. Heterozygous genotypes $113 \mathrm{YH}$ and $139 \mathrm{HR}$ of the EPHX1 gene tended to be associated with a decreased risk of asthma (empirical $P$-values were 0.059 and 0.065 , respectively).

No difference was found between cases and controls with respect to smoking status (66 asthmatic smokers versus 66 control smokers). Gene-environment interactions are given in Table 4. Notably, an absence of genotypes $462 \mathrm{IV}$ of the CYP1A1 gene $\left(p_{\mathrm{mc}}=0.050\right)$ and $432 \mathrm{LL}$ of the CYP1B1 gene $\left(p_{\mathrm{mc}}=0.013\right)$ and also possessing the GSTM1-null genotype $\left(p_{\mathrm{mc}}=0.023\right)$ were significantly associated with an increased risk of asthma only in smokers. In contrast, a carriage of genotypes 9896CG of the CYP2E1 gene $\left(p_{\mathrm{mc}}=0.022\right)$ and $213 \mathrm{RH}$ of the SULT1A1 gene $\left(p_{\mathrm{mc}}=0.046\right)$ and also the absence of genotypes $105 \mathrm{VV}$ of the GSTP 1 gene $\left(p_{\mathrm{mc}}=0.050\right)$ and $113 \mathrm{HH}$ of the $E P H X 1$ gene $\left(p_{\mathrm{mc}}=0.074\right)$ were associated with a decreased risk of asthma in nonsmokers. Meanwhile, these genotypes did not exert a protective effect in smokers. The CYP2J2 -50GT genotype was associated with an increased risk of asthma in all individuals not depending on their smoking status, but the risk for asthma was greater in smokers than in nonsmokers (OR 5.71 versus 4.34 , empirical $P$ values 0.024 and 0.013 , respectively).

It is recognized that the central problem in statistical modeling of gene-gene interactions is the dimensionality of the data, and large sample sizes are needed to detect effects with so many dimensions. Taking this issue into account, we used the MDR method ${ }^{38-42}$ as an alternative nonparametric statistical approach to investigate highorder gene-gene interactions in asthma. We have carried out an exhaustive search for all possible two-to-five-locus models among all 25 genetic polymorphisms of XME genes. The interaction between EPHX1 Y113H, CYP1B1 V432L and CYP2D6 G1934A loci showed the highest cross-validation consistency and the lowest prediction error among all gene-gene interaction models evaluated by MDR (Figure 1). Among five $n$-locus models, one three-locus model had a minimum prediction error of 37.8 (testing accuracy was 0.622) and a maximum cross-validation consistency of 10 (empirical $P$-value 0.05 , as determined by 1000 permutations). The dendrogram of gene-gene interactions (Figure 2) illustrates a complex hierarchical pattern of gene-gene interactions that was obtained by the MDR cluster technique. As can be seen from Figure 2, four relatively independent clusters of XME genes were observed.

It is known that associations between alleles at different loci (gametic disequilibrium), on the one hand, can provide important information about demographic and genetic events in the past, such as evolutionary forces governing the loci. ${ }^{45,46}$ On the other hand, they can be useful in locating disease susceptibility genes. ${ }^{47}$ We calculated gametic correlations between alleles of XME genes in healthy individuals and asthmatic patients (Supplementary Tables 4 and 5, respectively). The term gametic correlation (gametic disequilibrium) is the traditional term linkage disequilibrium to measure the extent of non-random association because such non-random association may be present between unlinked loci that are located at different chromosomes. ${ }^{48}$ Statistically meaningful gametic correlations were revealed in both study groups (the correlations are highlighted by bold face in Supplementary Tables 3 and 4). An important finding was that asthmatics had less number of gametic correlations than did healthy individuals. Another important finding is that many negative gametic correlations in healthy individuals were positive in asthmatics. Figure 3 
Table 2 Allele frequencies of the xenobiotic-metabolizing enzymes gene polymorphisms in asthmatics and controls

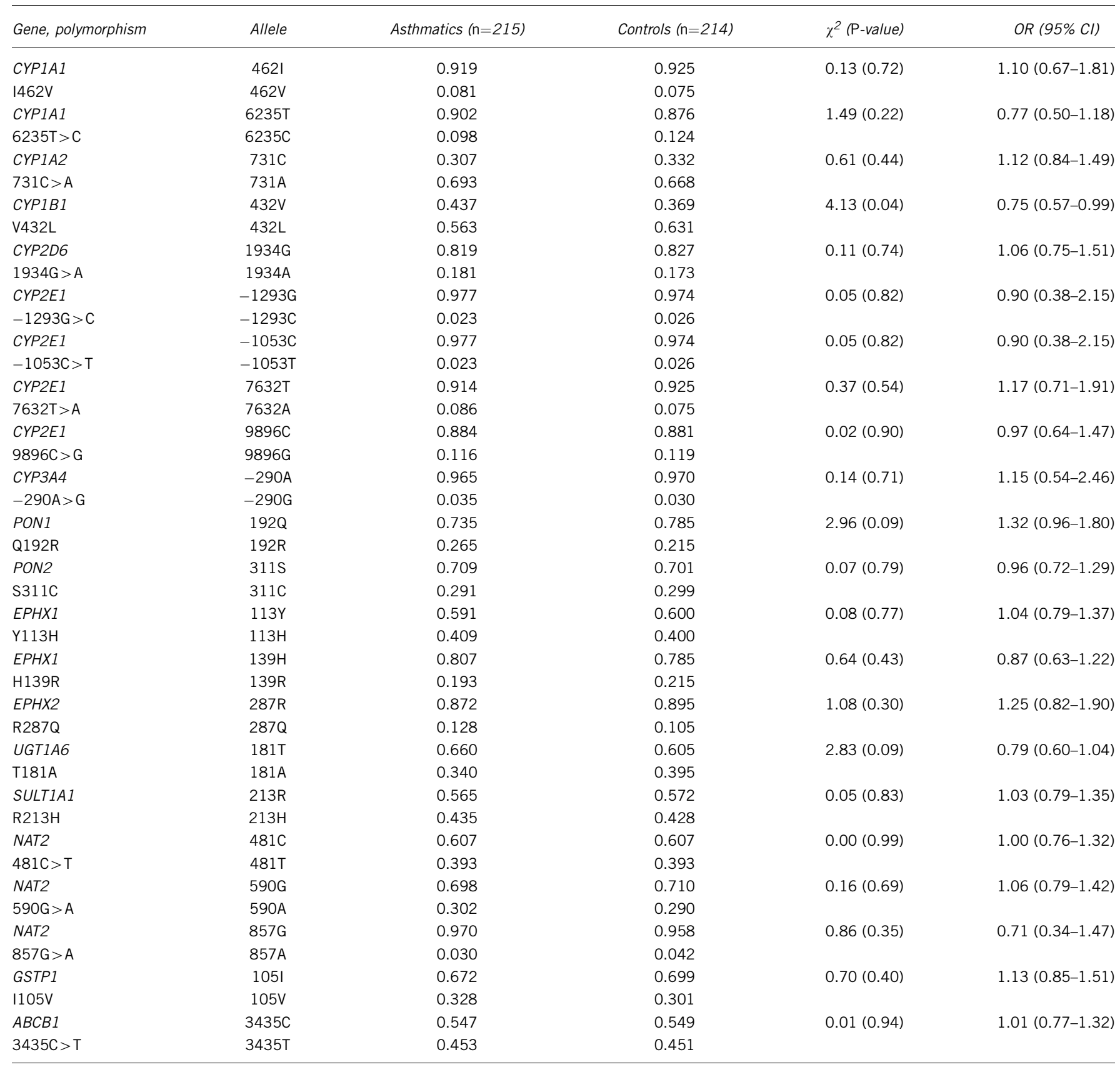

Abbreviations: $\mathrm{Cl}$, confidence interval; OR, odds ratio.

illustrates the differences between asthmatics and controls with respect to patterns of gametic disequilibrium between alleles of XME genes (the differences are highlighted by gray cells in Supplementary Table 5). An interesting finding was that a majority of gametic correlations observed in asthmatics involve XME genes that were found to be associated with the risk of asthma in our study.

\section{DISCUSSION}

A summary of the study findings

In this study, we have revealed for the first time that polymorphic genes for XMEs are important determinants of genetic susceptibility to bronchial asthma. In particular, single-nucleotide polymorphisms,
V432L of the CYP1B1 gene, Q192R of the PON1 gene and T181A of the UGT1A6 gene, were found to be significantly associated with the risk of asthma. The MDR method has obtained the best three-locus model for gene-gene interactions between the EPHX1 $\mathrm{Y} 113 \mathrm{H}$, CYP1B1 V432L and CYP2D6 G1934A loci in asthma at a maximum cross-validation consistency of $100 \%$ and a minimum prediction error of $37.8 \% \quad(P=0.05)$. A complex pattern of genomic interactions between genetic variants of 14 XMEs has been observed in asthmatics. We showed differences between asthmatics and controls with respect to patterns of gametic disequilibrium between alleles of XME genes. Furthermore, gene-environment interactions responsible for asthma susceptibility were also identified. 
Table 3 Genotype distributions of genes for xenobiotic-metabolizing enzymes in asthmatics and controls

\begin{tabular}{|c|c|c|c|c|c|}
\hline Gene, polymorphism & Genotype & Asthmatics $(n=215) \mathrm{n}(\%)^{\mathrm{a}}$ & Controls $(\mathrm{n}=214) \mathrm{n}(\%)^{a}$ & OR $(95 \% C l)^{b}$ & $\operatorname{aOR}(95 \% \mathrm{CI})^{\mathrm{c}}$ \\
\hline $1462 \mathrm{~V}$ & $462 \mathrm{IV}$ & $33(15.3)$ & $30(14.0)$ & $1.11(0.65-1.92)$ & $1.04(0.61-1.80)$ \\
\hline CYP1A1 & $6235 \mathrm{TT}$ & $174(80.9)$ & $162(75.7)$ & $0.73(0.46-1.17)$ & $0.74(0.46-1.17)$ \\
\hline \multirow[t]{2}{*}{$6235 \mathrm{~T}>\mathrm{C}$} & 6235TC & $40(18.6)$ & $51(23.8)$ & $0.73(0.46-1.17)$ & $0.73(0.46-1.17)$ \\
\hline & $6235 \mathrm{CC}$ & $1(0.5)$ & $1(0.5)$ & - & - \\
\hline $731 C>A$ & 731AA & $106(49.3)$ & $93(43.5)$ & $1.27(0.86-1.85)$ & $1.25(0.85-1.84)$ \\
\hline CYP1B1 & $432 \mathrm{VV}$ & $38(17.7)$ & $28(13.1)$ & $0.70(0.41-1.19)$ & $0.67(0.40-1.17)$ \\
\hline \multirow[t]{2}{*}{ V432L } & $432 \mathrm{VL}$ & $112(52.1)$ & $102(47.7)$ & $1.19(0.82-1.74)$ & $1.19(0.81-1.74)$ \\
\hline & 432LL & $65(30.2)$ & $84(39.3)$ & $0.67(0.45-1.00)$ & $0.67(0.44-0.99)$ \\
\hline CYP2D6 & 1934GG & $144(67.0)$ & $146(68.2)$ & $1.06(0.70-1.59)$ & $1.08(0.72-1.63)$ \\
\hline $1934 G>A$ & 1934GA & $64(29.8)$ & $62(29.0)$ & $1.04(0.67-1.61)$ & $1.07(0.70-1.63)$ \\
\hline CYP2E1 & $-1053 C \mathrm{C}$ & $205(95.4)$ & 203 (94.9) & $0.90(0.37-2.21)$ & $0.78(0.31-1.94)$ \\
\hline \multirow{2}{*}{$-1053 C>T$} & $-1053 \mathrm{CT}$ & $10(4.7)$ & $11(5.1)$ & $0.90(0.37-2.21)$ & $0.78(0.31-1.94)$ \\
\hline & $-1053 \mathrm{TT}$ & - & - & - & - \\
\hline CYP2E1 & $7632 \mathrm{TT}$ & $180(83.7)$ & $182(85.1)$ & $1,11(0.65-1.89)$ & $1.08(0.63-1.83)$ \\
\hline \multirow[t]{2}{*}{$7632 \mathrm{~T}>\mathrm{A}$} & 7632TA & 33 (15.4) & $32(15.0)$ & $1.03(0.59-1.81)$ & $1.01(0.59-1.73)$ \\
\hline & 7632AA & $2(0.9)$ & $0(0.0)$ & - & - \\
\hline CYP2E1 & $9896 \mathrm{CC}$ & $167(77.7)$ & $165(77.1)$ & $0.97(0.59-1.58)$ & $0.89(0.56-1.42)$ \\
\hline \multirow[t]{2}{*}{$9896 C>G$} & 9896CG & $46(21.4)$ & 47 (22.0) & $0.97(0.61-1.53)$ & $0.89(0.56-1.42)$ \\
\hline & 9896GG & $2(0.9)$ & $2(0.9)$ & - & - \\
\hline СУРЗА4 & $-290 A A$ & 201 (93.5) & 201 (93.9) & $1.08(0.47-2.48)$ & $1.03(0.46-2.30)$ \\
\hline \multirow[t]{2}{*}{$-290 A>G$} & $-290 A G$ & $13(6.1)$ & $13(6.1)$ & - & - \\
\hline & $-290 G G$ & $1(0.5)$ & $0(0.0)$ & - & - \\
\hline \multirow[t]{2}{*}{ Y113H } & $113 \mathrm{YH}$ & $72(33.5)$ & 89 (41.6) & $0.71(0.48-1.05)$ & $0.69(0.46-1.02)$ \\
\hline & $113 \mathrm{HH}$ & $52(24.2)$ & $41(19.2)$ & $1.35(0.85-2.14)$ & $1.30(0.81-2.08)$ \\
\hline$E P H X 1$ & $139 \mathrm{HH}$ & $142(66.0)$ & $128(59.8)$ & $0.77(0.52-1.13)$ & $0.76(0.51-1.13)$ \\
\hline \multirow[t]{2}{*}{ H139R } & $139 \mathrm{HR}$ & $63(29.3)$ & $80(37.4)$ & $0.69(0.46-1.04)$ & $0.67(0.45-1.02)$ \\
\hline & 139RR & $10(4.7)$ & $6(2.8)$ & $1.69(0.60-4.76)$ & $1.91(0.67-5.42)$ \\
\hline$E P H X 2$ & $287 R R$ & $162(75.3)$ & $170(79.4)$ & $1.26(0.80-1.99)$ & $1.29(0.81-2.03)$ \\
\hline \multirow[t]{2}{*}{ R287Q } & $287 R Q$ & $51(23.7)$ & $43(20.1)$ & $1.24(0.78-1.96)$ & $1,29(0.79-2.00)$ \\
\hline & $287 Q Q$ & $2(0.9)$ & $1(0.5)$ & $0.50(0.04-5.62)$ & $0.51(0.05-5.80)$ \\
\hline UGT1A6 & $181 \mathrm{TT}$ & 90 (41.9) & $83(38.8)$ & $0.88(0.60-1.30)$ & $0.88(0.60-1.31)$ \\
\hline \multirow[t]{2}{*}{ T181A } & $181 \mathrm{TA}$ & $104(48.4)$ & $93(43.5)$ & $1.22(0.83-1.79)$ & $1.22(0.83-1.80)$ \\
\hline & $181 \mathrm{AA}$ & $21(9.8)$ & $38(17.8)$ & $0.50(0.28-0.89)$ & $0.50(0.28-0.90)$ \\
\hline SULT1A1 & 213RR & $71(33.0)$ & $68(31.8)$ & $0.94(0.63-1.42)$ & $0.91(0.61-1.38)$ \\
\hline $\mathrm{R} 213 \mathrm{H}$ & $213 \mathrm{RH}$ & $101(47.0)$ & 109 (50.9) & $0.85(0.58-1.25)$ & $0.82(0.56-1.21)$ \\
\hline & $213 \mathrm{HH}$ & $43(20.0)$ & 37 (17.3) & $1.20(0.73-1.95)$ & $1.21(0.74-1.98)$ \\
\hline NAT2 & $481 \mathrm{CC}$ & $78(36.3)$ & $80(37.4)$ & $1.05(0.70-1.57)$ & $1.03(0.69-1.54)$ \\
\hline $481 C>T$ & $481 \mathrm{CT}$ & $105(48.3)$ & $100(46.7)$ & $1.09(0.74-1.60)$ & $1.09(0.74-1.60)$ \\
\hline & $481 T \mathrm{TT}$ & $32(14.9)$ & 34 (15.9) & $0.93(0.55-1.57)$ & $0.90(0.53-1.52)$ \\
\hline NAT2 & $590 \mathrm{GG}$ & $104(48.4)$ & $111(51.9)$ & $1.15(0.79-1.68)$ & $1.14(0.78-1.68)$ \\
\hline $590 G>A$ & $590 \mathrm{GA}$ & $92(42.8)$ & $82(38.3)$ & $1.20(0.82-1.77)$ & $1.18(0.80-1.75)$ \\
\hline & 590AA & $19(8.8)$ & $21(9.8)$ & $0.89(0.46-1.72)$ & $0.93(0.48-1.78)$ \\
\hline NAT2 & $857 G G$ & $202(94.0)$ & $197(92.1)$ & $0.75(0.35-1.58)$ & $0.77(0.36-1.65)$ \\
\hline $857 G>A$ & $857 \mathrm{GA}$ & $13(6.0)$ & $16(7.5)$ & $0.80(0.37-1.71)$ & $0.82(0.38-1.77)$ \\
\hline
\end{tabular}


Table 3 Continued

\begin{tabular}{|c|c|c|c|c|c|}
\hline Gene, polymorphism & Genotype & Asthmatics $(n=215) \mathrm{n}(\%)^{a}$ & Controls $(n=214) n(\%)^{a}$ & OR $(95 \% C l)^{b}$ & $\operatorname{aOR}(95 \% \mathrm{Cl})^{\mathrm{c}}$ \\
\hline & 857AA & $0(0.0)$ & $1(0.5)$ & - & - \\
\hline GSTM1 & Expressor & $101(47.0)$ & $108(50.5)$ & $1.15(0.79-1.68)$ & $1.15(0.79-1.69)$ \\
\hline \multicolumn{6}{|l|}{ Null } \\
\hline & Null & $114(53.0)$ & $106(49.5)$ & $1.15(0.79-1.68)$ & $1.15(0.79-1.69)$ \\
\hline GSTT1 & Expressor & $185(86.0)$ & $184(86.0)$ & - & - \\
\hline Null & Null & $30(14.0)$ & $30(14.0)$ & - & - \\
\hline GSTP1 & $105 I I$ & $96(44.7)$ & $104(48.6)$ & $1.17(0.80-1.71)$ & $1.18(0.80-1.73)$ \\
\hline \multirow[t]{2}{*}{ I105V } & $105 I V$ & $97(45.1)$ & $91(42.5)$ & $1.11(0.76-1.63)$ & $1.11(0.75-1.63)$ \\
\hline & 105VV & $22(10.2)$ & $19(8.9)$ & $0.85(0.45-1.62)$ & $0.83(0.43-1.60)$ \\
\hline$A B C B 1$ & $3435 \mathrm{CC}$ & $65(30.2)$ & $64(29.9)$ & $0.98(0.63-1.53)$ & $0.99(0.64-0.52)$ \\
\hline \multirow[t]{2}{*}{$3435 \mathrm{C}>\mathrm{T}$} & $3435 \mathrm{CT}$ & $105(48.8)$ & $107(50.0)$ & $0.95(0.65-1.39)$ & $0.94(0.64-1.37)$ \\
\hline & 3435TT & $45(20.9)$ & $43(20.1)$ & $1.05(0.65-0.70)$ & $1.10(0.68-1.78)$ \\
\hline
\end{tabular}

Abbreviations: aOR; adjusted odds ratio; $\mathrm{Cl}$, confidence interval; OR, odds ratio.

aAbsolute number and percentage of individuals with particular genotype.

bOR with $95 \% \mathrm{Cls}$.

'OR adjusted for age and gender with $95 \% \mathrm{Cls}$.

Table 4 A summary of gene-environment interactions in asthma ${ }^{a}$

\begin{tabular}{|c|c|c|c|c|c|c|}
\hline \multirow[b]{3}{*}{$X M E$ genotypes } & \multicolumn{4}{|c|}{ Smoking status (Yes, No) } & \multicolumn{2}{|c|}{ Odds ratios, OR $(95 \% \mathrm{Cl})$} \\
\hline & \multicolumn{2}{|c|}{ Asthmatics $(\mathrm{n}=194)$} & \multicolumn{2}{|c|}{ Controls $(\mathrm{n}=167)$} & \multirow{2}{*}{ Nonsmokers } & \multirow{2}{*}{ Smokers } \\
\hline & No & Yes & No & Yes & & \\
\hline Absence of CYP1A1 462IV & $106(82.8)$ & $60(90.9)$ & $91(90.1)$ & $52(78.8)$ & $0.53(0.24-1.18) P=0.11$ & $2.69(0.97-7.51) P=0.05$ \\
\hline Absence of CYP1B1 432LL & $85(66.4)$ & $52(78.8)$ & $66(65.3)$ & $38(57.6)$ & $1.05(0.60-1.82) P=0.87$ & $2.74(1.27-5.89) P=0.01$ \\
\hline Presence of CYP2E1 9896CG & $25(19.5)$ & $16(24.2)$ & $33(32.7)$ & $11(16.7)$ & $0.50(0.27-0.91) P=0.02$ & $1.60(0.68-3.77) P=0.28$ \\
\hline Presence of $C Y P 2 J 2-50 G T$ & $15(11.7)$ & $10(15.2)$ & $3(3.0)$ & $2(3.0)$ & $4.34(1.22-15.42) P=0.01$ & $5.71(1.20-27.19) P=0.02$ \\
\hline Absence of $E P H X 1113 \mathrm{HH}$ & $95(74.2)$ & $52(78.8)$ & $85(84.2)$ & $48(72.7)$ & $0.54(0.28-1.05) P=0.07$ & $1.39(0.63-3.10) P=0.42$ \\
\hline Presence of SULT1A1 213RH & $52(40.6)$ & $39(59.1)$ & $55(54.5)$ & $32(48.5)$ & $0.57(0.34-0.97) P=0.04$ & $1.53(0.77-3.05) P=0.22$ \\
\hline Presence of GSTM1 null & $62(48.4)$ & $41(62.1)$ & $53(52.5)$ & $28(42.4)$ & $0.85(0.50-1.43) P=0.54$ & $2.23(1.11-4.47) P=0.02$ \\
\hline Absence of GSTP1 105VV & $112(87.6)$ & $61(92.4)$ & $96(95.0)$ & $55(83.3)$ & $0.36(0.13-1.03) P=0.05$ & $2.44(0.80-7.46) P=0.11$ \\
\hline
\end{tabular}

Abbreviations: $\mathrm{Cl}$, confidence interval; OR, odds ratio; XME, xenobiotic-metabolizing enzyme.

aThe table summarizes gene-environmental interactions that showed significance level $P<0.10$ ( $\chi^{2}$-test).

\section{A complexity of genomic interactions between XME genes determining susceptibility to bronchial asthma}

Interestingly, EPHX1 and CYP1B1 genes that showed associations with susceptibility to asthma in our case-control analysis were included in a statistical model of gene-gene interactions obtained using the MDR method. In contrast, the third gene in the model, the CYP2D6 gene, was not associated with asthma risk in case-control analysis. This finding clearly indicates epistasis: the effect of one gene may not be disclosed if the effect of another gene is not considered. ${ }^{41}$ CYP2D6 is known to be responsible for the metabolism of a large number of clinically used drugs. ${ }^{49}$ Notably, the MDR analysis has revealed a strong synergism in the interaction between CYP2D6 and EPHX1 genes in determining asthma risk, suggesting that the gene-gene effect may be driven by a true interaction, rather than by the main effect from the EPHX1 gene. Despite the three genes being included in the best MDR model, the CYP1B1 gene showed independence from the interaction between CYP2D6 and EPHX1 genes (Figure 2). Meanwhile, the CYP1B1 gene interacted with the UGT1A6 gene, which was associated with the risk of asthma in our case-control analysis. Although it is very difficult to interpret biologically gene-gene interactions obtained by the MDR analysis, the gene-gene interaction makes mechanistic sense, because these genes are involved in the same metabolic detoxification pathway (Supplementary Tables 1 and 2). It seems that the integrated function of the EPHX1, CYP1B1 and CYP2D6 genes and their products promotes a coordinated metabolism of common xenobiotics such as PAH and heterocyclic compounds in the lungs and airways, where these genes are vitally expressed. ${ }^{19,50}$ Interestingly, the cluster MDR analysis showed high-order gene-gene interactions between 14 genes for biotransformation enzymes. This finding illustrates a polygenic nature of interactions between XME genes contributing to asthma pathogenesis. Another interesting finding is that several XME genes, which have been found to be associated with asthma risk in this and some other studies, ${ }^{43,51}$ represent the independent clusters of interacting genes (Figure 2), thereby showing complex genomic interactions between biotransformation genes that constitute the polygenic basis of asthma.

The disease-specific architecture of gametic correlations between allelic variants of XME genes

The gametic correlations between XME loci at different chromosomes were the subject of great interest, as they concern a possible 
a

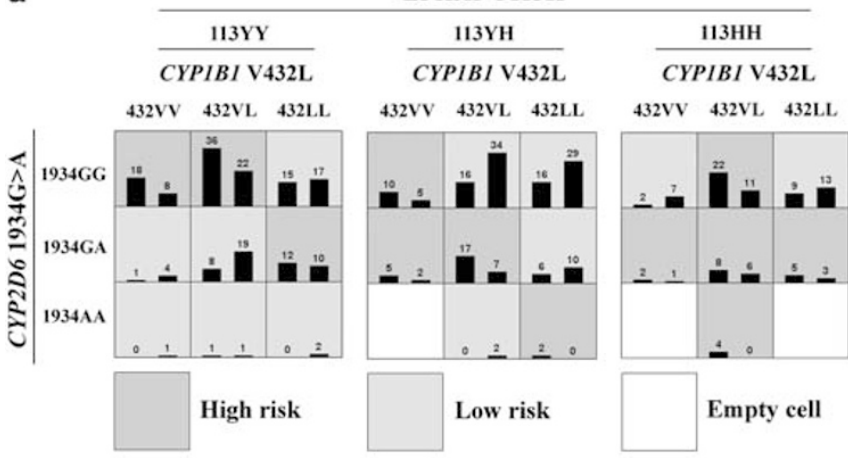

b

\begin{tabular}{|c|c|c|c|c|}
\hline $\begin{array}{c}\text { No of } \\
\text { locus per } \\
\text { model }\end{array}$ & $\begin{array}{c}\text { XME gene-gene interactions } \\
\text { obtained by multifactor } \\
\text { dimensionality reduction method }\end{array}$ & $\begin{array}{c}\text { Testing } \\
\text { accuracy }\end{array}$ & $\begin{array}{c}\text { Sign test } \\
\text { (p-value) }\end{array}$ & $\begin{array}{c}\text { Cross- } \\
\text { validation } \\
\text { consistency }\end{array}$ \\
\hline 1 & CYPIBI V432L & 0.447 & $3(0.945)$ & $3 / 10$ \\
\hline 2 & CYP2D6 1934G $>$ A, EPHXI Y113H & 0.523 & $5(0.623)$ & $8 / 10$ \\
\hline 3 & $\begin{array}{r}\text { CYPIBI V432L, CYP2D6 1934G }>\text { A, } \\
\text { EPHXI Y113H }\end{array}$ & $\mathbf{0 . 6 2 2}$ & $10(0.001)$ & $10 / 10$ \\
\hline 4 & $\begin{array}{c}\text { CYPIBI V432L, CYP2D6 1934G }>\text { A, } \\
\text { EPHXI Y113H, EPHXI H139R }\end{array}$ & 0.584 & $9(0.010)$ & $6 / 10$ \\
\hline 5 & $\begin{array}{c}\text { CYPIA2 731C }>\text { A, CYPIBI V432L, } \\
\text { EPHXI Y113H, UGTIA6 T181A, } \\
\text { SULTIAI R213H }\end{array}$ & 0.452 & $3(0.945)$ & $3 / 10$ \\
\hline
\end{tabular}

Figure 1 (a) Summary of three-locus xenobiotic-metabolizing enzyme (XME) genotype combinations associated with high risk and low risk for bronchial asthma, along with the corresponding distribution of cases (left bars in boxes) and of controls (right bars in boxes), for each multilocus-genotype combination. The patterns of high-risk and low-risk cells differ across each of the different multilocus dimensions, thereby showing the epistatic genegene interactions. (b) A summary of the best one-to-five-locus model of the XME gene-gene interactions with cross-validation consistency and prediction error per the $n$-locus model that have been obtained by the multifactordimensionality reduction of our data set. The multilocus model with maximum cross-validation consistency (10/10) and minimum prediction error (maximum testing accuracy is 0.622 ) is indicated in gray cells (MonteCarlo simulation $P$-value $<0.05$ ).

evolutional conservation of beneficial allelic combinations that provided a most optimal adaptive response to constant changes in the environment. Taking biological functions of the XME into account, it would be reasonable to assume that gametic correlations between XME genes have conferred evolutionary and developmental advantages, perhaps as a defense in maintaining homeostatic responses to toxic chemicals, such as $\mathrm{PAH}$, heterocyclic aromatic amines (HAAs) and other chemical compounds. The gametic correlations were in accordance with the assumption that critical biological functions, such as a balance of toxification/detoxification processes in the metabolism of common xenobiotics, have evolved into an evolutionary optimum. Negative gametic correlations between alleles of XME genes found in healthy individuals suggest that individuals having evolutionarily conserved interactions between loci have maximal efficacy of toxification/detoxification processes and, in turn, are less susceptible to a damage by environmental chemicals. In other words, an effect of one allele increasing the toxicity of a chemical is compensated by an effect of another allele increasing the detoxification of a reactive intermediate. We propose to define this feature as an evolutionarily conserved 'genetic agreement' between various biotransformation enzymes maintaining a tune balance of toxification and detoxification processes, a known condition, when lipophilic xenobiotics of the envir- onment are metabolically activated by phase I enzymes and thereafter detoxified by phase II enzymes. ${ }^{49}$ However, we observed very specific gametic correlations between alleles of several XME genes in asthmatics in comparison with healthy individuals (Supplementary Tables 4 and 5, Figure 3). Interestingly, many of XME genes showing the difference in patterns of gametic correlations have been found to be associated with risk of asthma in this study and in several studies published in literature. Therefore, gametic correlations between the disease-causing alleles, which occur specifically in asthmatics, may show an imbalance between toxification and detoxification processes, making such individuals more susceptible to environmental chemicals that are known to have a role in asthma etiology. ${ }^{11,14-16,18}$ It is important to notify that specific gametic correlations found between XME genes in asthmatics could be considered as a reflection of the disease-related patterns of genomic sequences responsible for the activation of cis-acting regulatory elements, such as xenobiotic responsive elements and antioxidant responsive elements. These DNA sequences are highly conserved in most XME families and are known to regulate the expression profiles of XMEs in response to chemicals. ${ }^{52}$ Certainly, the specific gametic correlations found in both study groups may be indirectly related to evolutionary forces. Instead, the differences in gametic correlations between the groups are suggestive of recent ecological and genetic events that have maintained such variable linkage disequilibrium between genes encoding XMEs in humans. Although humans have been exposed to airborne particles throughout their evolution, such exposure has increased dramatically over the last century because of anthropogenic sources, thereby resulting in large-scale releases of naturally occurring chemicals into the environment, in addition to the production and release of new substances unlike any that had existed before. Although not much is known about the actual mechanisms and factors responsible for interindividual differences in the gametic disequilibrium between SNPs in human genome, the results of our study may provide important biological information with regard to the common molecular evolution, physiological significance and in vivo functional relationships of genes encoding XMEs in humans.

\section{Importance of gene-environment interactions in asthma pathogenesis}

Although we have not revealed any difference between asthmatics and healthy controls with respect to smoking status, associations of eight polymorphisms of XME genes with the risk of asthma were found in smokers. For instance, the absence of genotypes $462 \mathrm{IV}$ of the CYP1A1 and 432LL of the CYP1B1 gene was significantly associated with increased risk of asthma only in smokers. Taken together, these data clearly show gene-environment interactions, that is, interactions between XME genes-cigarette smoke chemicals, which seem to be important in the etiology of bronchial asthma. ${ }^{7}$ Although cigarette smoking alone did not increase the risk of bronchial asthma, the results suggest that exposure to chemicals may modify the association of asthma with several polymorphic genes known to activate or detoxify PAHs and other compounds found in tobacco smoke. The mechanisms by which environmental chemicals can induce host sensitization and asthma development are other important issues that need to be discussed. It was suggested that most airborne pollutants function as mucosal adjuvants and, in interacting with both innate and adaptive immune cells, skew the immune response to inhaled antigens toward a T-helper type 2-like phenotype. ${ }^{53}$ For instance, diesel exhaust particles (DEPs) are known to be a major component of suspended atmospheric pollutants and have been shown to initiate and exacerbate airway allergic responses that can 


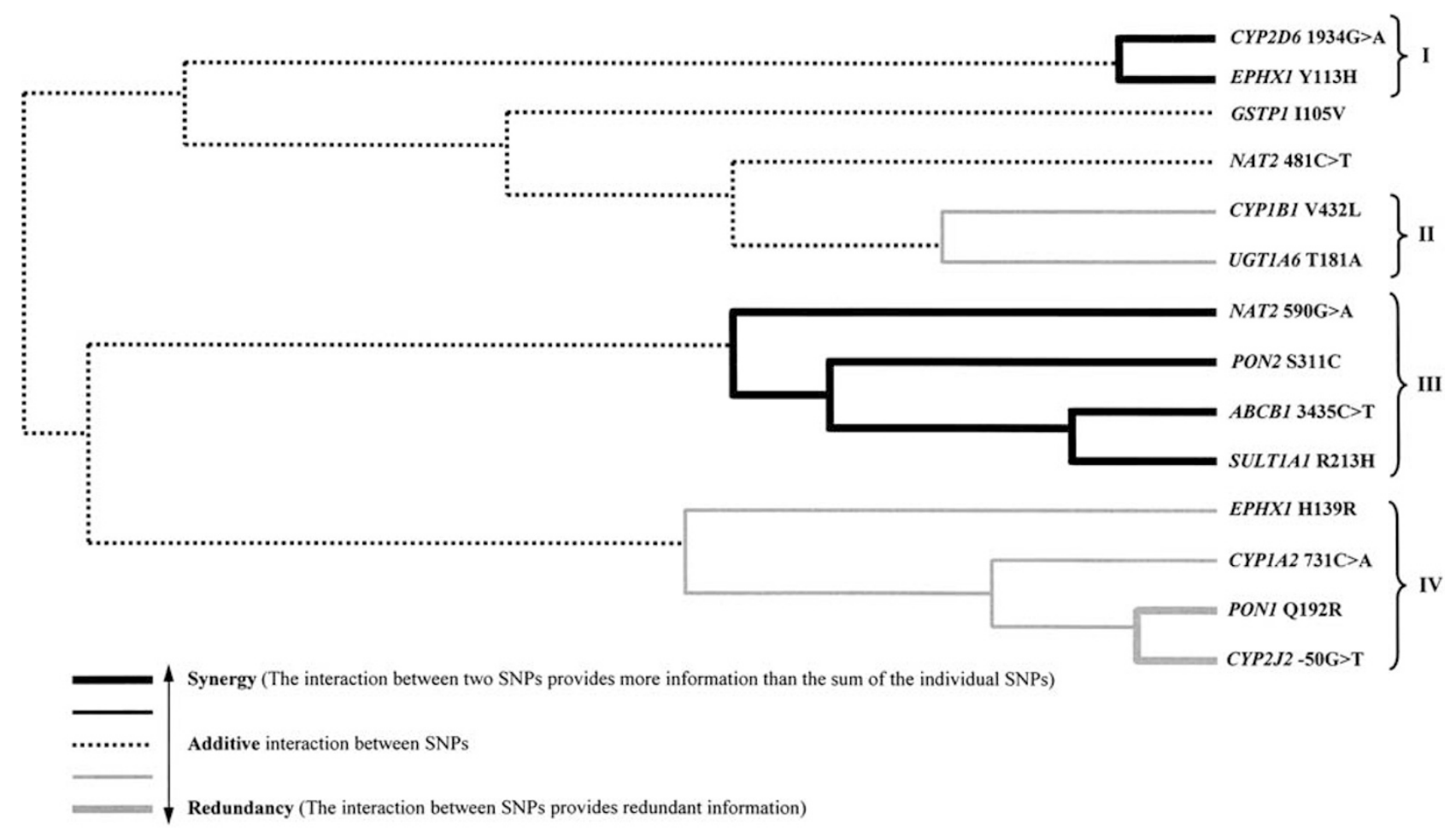

Figure $2 \mathrm{~A}$ dendrogram shows a complex pattern of interactions between 14 polymorphic genes of xenobiotic-metabolizing enzymes, which forms four independent clusters of the genes. The cluster I comprises the EPHX1 Y113H and CYP2D6 G1934A loci, which had the highest degree of synergy in their interactions to determine the susceptibility asthma. A lesser degree of synergy in gene-gene interactions was found for the $A B C B 13435 C>T$, SULT1A1 R213H, PON2 S311C and NAT2 590G > A loci (the cluster III). The cluster IV including the CYP2J2 -50G/T and PON1 Q192R loci had the highest degree of redundancy in their interactions, which also seems to have a role in the development of asthma. The latter gene polymorphisms were also found to interact with the CYP1A2 731C $>A$ and EPHX1 H139R loci in the same manner, but to a lesser degree. The low degree of redundancy in gene-gene interactions was observed between the CYP1B1 V432L and UGT1A6 T181A loci (the cluster II). The lines used in the dendrogram comprise a spectrum of lines representing a continuum from Synergy (black) to Redundancy (gray). The lines range from bold black, representing a high degree of synergy (positive information gain), thin black, representing a lesser degree, and dotted line representing the midway point between synergy and redundancy. On the redundancy end of the spectrum, the highest degree is represented by bold gray (negative information gain) with a lesser degree represented by thin gray. SNP, single-nucleotide polymorphism.

directly target multiple airway cells, including epithelial cells, mast cells, macrophages and lymphocytes, and induce the production of cytokines, chemokines and other inflammatory mediators associated with the asthmatic phenotype. ${ }^{53-55}$ DEPs can initiate and exacerbate airway allergic responses through oxidative stress and reactive oxygen species resulting in an enhanced IgE and histamine production. $8,13,56,57$ In addition to this adjuvant effect, DEPs are also known to induce or augment IgE production by acting directly on B cells. ${ }^{53,56}$

The information gleaned from our study should be seen as a hypothesis-generating observation of a complex involvement of XME genes in molecular mechanisms of asthma, the results being obtained for the first time. A majority of the associations of XME genes with asthma were not strong, thereby showing small-to-modest effects of these genes on the asthmatic phenotype. It was not surprising as small-to-modest effects of common genetic variations are characteristics of any polygenic disease, including bronchial asthma. Importantly, all genes that were found to be associated with asthma in this study are expressed in the lungs and airways, suggesting their significance for the metabolism of xenobiotics inspired in the respiratory tract from the environment and a possible involvement in the pathogenesis of asthma. The study results point to the potential relevance of toxicogenomic mechanisms of bronchial asthma in the modern world, and may thereby provide a novel direction in the genetic research of the respiratory disease, which perhaps will improve our understanding of the major causes responsible for a sharp increase in the prevalence of the disease worldwide in the past few decades. Further investigations addressing this question may provide important insights into the molecular mechanisms of bronchial asthma. Undoubtedly, a complete understanding of the causative role of environmental chemicals in the development of asthma will require conducting both experimental and clinical studies to substantiate their participation in the molecular mechanisms underlying the disease phenotype. Further population-based studies with larger sample sizes are needed to confirm the associations of genetic polymorphisms of XME genes with the risk of bronchial asthma. Recent advances in genomic and proteomic research could provide a comprehensive approach to elucidating toxicogenomic mechanisms of asthma at a sophisticated level of molecular detail already in the nearest future. Using global transcriptional profiling of XME genes to link toxic challenges with specific batteries of mRNA would have the potential to provide insights into the toxicogenomic mechanisms of asthma and to identify sensitive biomarkers of exposure responsible for disease etiology. 
Interlocus gametic correlations between the xenobiotic metabolizing enzymes genes in healthy subjects

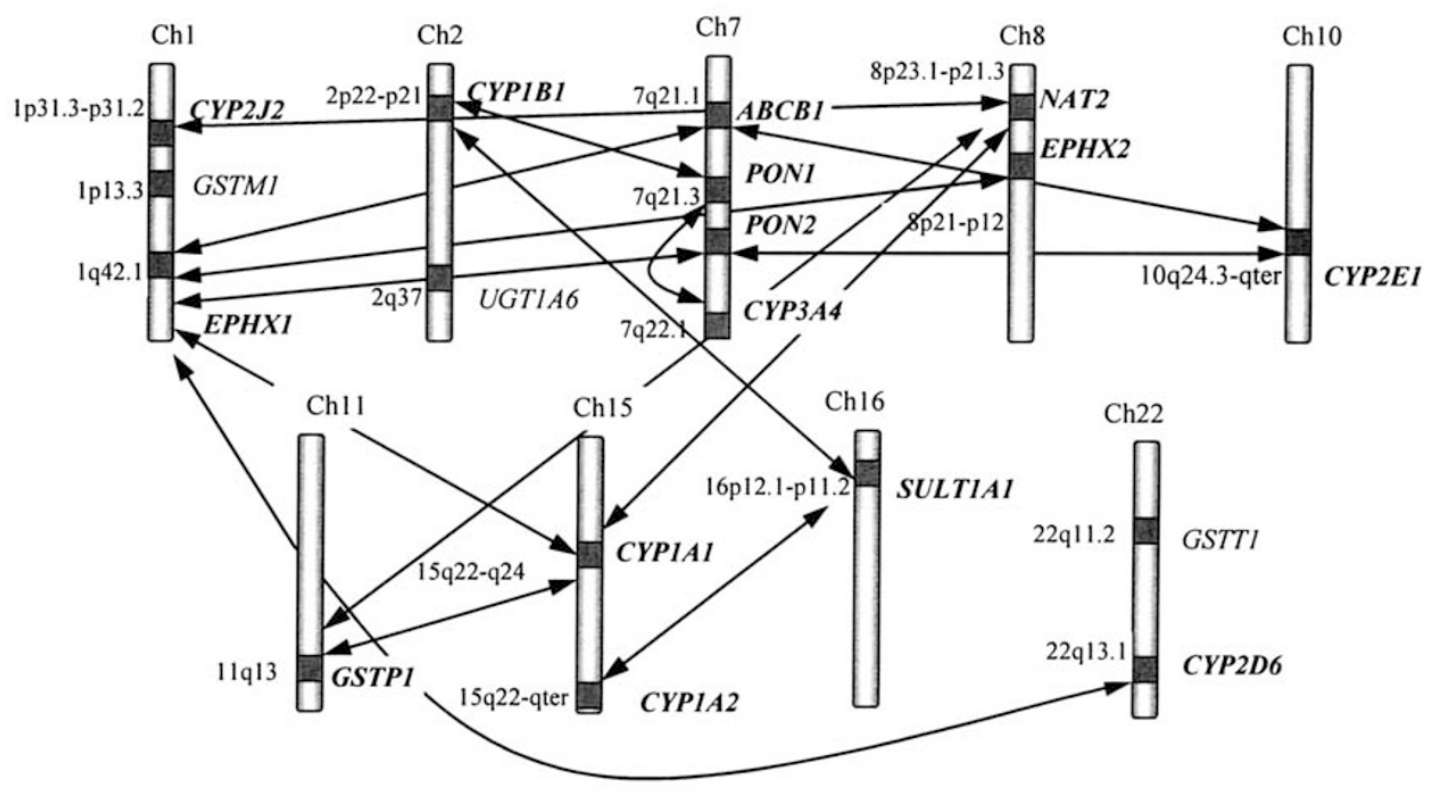

Interlocus gametic correlations between the xenobiotic metabolizing enzymes genes in bronchial asthma

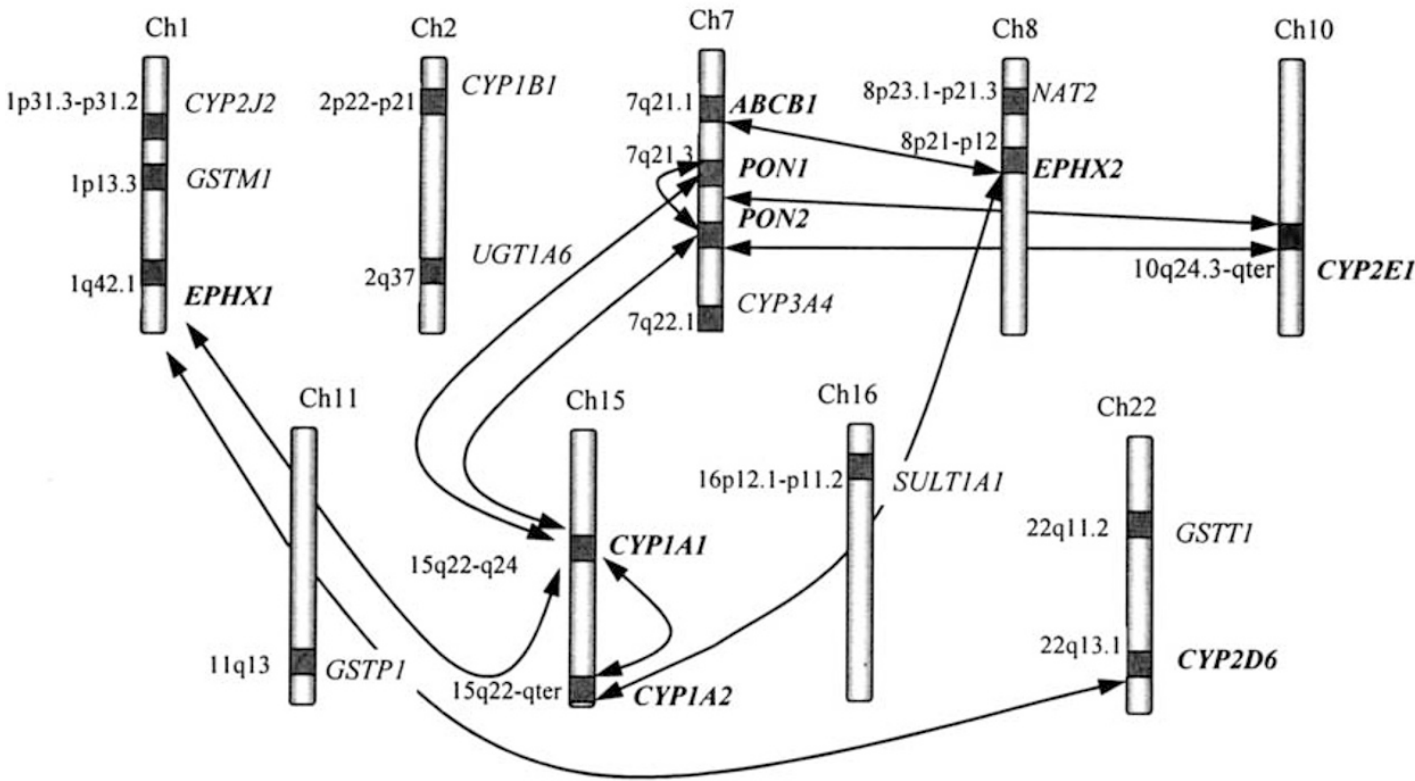

Figure 3 The figure schematically represents interlocus gametic correlations between the xenobiotic-metabolizing enzyme (XME) genes in healthy subjects (above) and patients with asthma (below). Notably, numerous gametic correlations were observed between various XME gene polymorphisms in healthy subjects, suggesting evolutionarily preserved synergy or functional integration of phase I and II enzymes in the metabolism of common xenobiotics. In contrary, a strong disintegration in the gametic correlations between XME gene polymorphisms was observed in asthmatics. A majority of gametic correlations between allelic variants of XME genes, which are observed specifically in asthmatics, involve those genes that have been shown to be associated with asthma susceptibility in this and in some other studies.

\section{ACKNOWLEDGEMENTS}

This research was supported in part by a grant from the President of Russian Federation (MD-3571.2008.7). We thank Drs Mikhail Kozhuhov and Valery Panfilov from the Kursk Regional Clinical Hospital for their assistance in assembling patients with asthma, as well as for their help in diagnosis of the disease. We thank Professor Jason H Moore from Dartmouth Medical School and Dartmouth College (USA) for his expert assistance in the MDR statistical analysis and for helpful comments on interpretation of the MDR data. 
1 Moffatt, M. F. Genes in asthma: new genes and new ways. Curr. Opin. Allergy. Clin. Immunol. 8, 411-417 (2008).

2 Zhang, J., Paré, P. D. \& Sandford, A. J. Recent advances in asthma genetics. Respir. Res. 15, 4 (2008)

3 Bossé, Y. \& Hudson, T. J. Toward a comprehensive set of asthma susceptibility genes. Annu. Rev. Med. 58, 171-184 (2007).

4 Vercelli, D. Advances in asthma and allergy genetics in 2007. J. Allergy Clin. Immunol. 122, 267-271 (2008)

5 Szalai, C., Ungvári, I., Pelyhe, L., Tölgyesi, G. \& Falus, A. Asthma from a pharmacogenomic point of view. Br. J. Pharmacol. 153, 1602-1614 (2008).

6 Selgrade, M. K., Lemanske, R. F. Jr., Gilmour, M. I., Neas, L. M., Ward, M. D. \& Henneberger, P. K. et al. Induction of asthma and the environment: what we know and need to know. Environ. Health Perspect. 114, 615-619 (2006).

7 Castro-Giner, F., Kauffmann, F., de, Cid, R. \& Kogevinas, M. Gene-environment interactions in asthma. Occup. Environ. Med. 63, 776-786 (2006).

8 Kelly, F. J. \& Sandstom, T. Air pollution, oxidative stress and allergic response. Lancet 363, 95-99 (2004).

9 Peden, D. B. The epidemiology and genetics of asthma risk associated with air pollution. J. Allergy Clin. Immunol. 115, 213-219 (2005).

10 Koenig, J. Q., Mar, T. F. \& Allen, R. W. Pulmonary effects of indoor- and outdoor-generated particles in children with asthma. Environ. Health Perspect. 113, 499-503 (2005).

11 Salam, M. T., Islam, T. \& Gilliland, F. D. Recent evidence for adverse effects of residential proximity to traffic sources on asthma. Curr. Opin. Pulm. Med. 14, 3-8 (2008).

12 Riedl, M. A. The effect of air pollution on asthma and allergy. Curr. Allergy Asthma Rep. 8, 139-146 2008

13 Gilliland, F. D., Li, Y. F., Saxon, A. \& Diaz-Sanchez, D. Effect of glutathione-Stransferase $\mathrm{M} 1$ and $\mathrm{P} 1$ genotypes on xenobiotic enhancement of allergic responses: randomised, placebo-controlled crossover study. Lancet 363, 119-125 (2004).

14 Lee, Y. L., Lin, Y. C., Lee, Y. C., Wang, J. Y., Hsiue, T. R. \& Guo, Y. L. Glutathione Stransferase $\mathrm{P} 1$ gene polymorphism and air pollution as interactive risk factors for childhood asthma. Clin. Exp. Allergy 34, 1707-1713 (2004).

15 Solodilova, M. A., Ivanov, V. P., Polonikov, A. V., Khoroshaya, I. V., Kozhuhov, M. A. \& Panfilov, V. I. Heterozygosity of 198Leu mutant allele in glutathione peroxidase-1 gene as a risk factor of bronchial asthma associated with smoking. Ter. Arkh. 79, 33-36 (2007).

16 Polonikov, A. V., Ivanov, V. P., Solodilova, M. A., Khoroshaya, I. V., Kozhuhov, M. A. \& Panfilov, V. I. The relationship between polymorphisms in the glutamate cysteine ligase gene and asthma susceptibility. Respir. Med. 101, 2422-2424 (2007).

17 Ivanov, V. P., Solodilova, M. A., Polonikov, A. V., Khoroshaya, I. V., Kozhuhov, M. A. \& Panfilov, V. I. Association analysis of C242T and A640G polymorphisms in the gene for p22phox subunit of NADPH oxidase with the risk of bronchial asthma: a pilot study. Rus. J. Genet. 44, 601-608 (2008).

18 Polonikov, A. V., Ivanov, V. P., Solodilova, M. A., Kozhuhov, M. A. \& Panfilov, V. I. Tobacco smoking, fruit and vegetable intake modify association between $-21 \mathrm{~A}>\mathrm{T}$ polymorphism of catalase gene and risk of bronchial asthma. J. Asthma 46, 217-224 (2009).

19 Zhang, J. Y., Wang, Y. F. \& Prakash, C. Xenobiotic-metabolizing enzymes in human lung. Curr. Drug Metab. 7, 939-948 (2006).

20 Hong, Y. C., Park, H. S. \& Ha, E. H. Influence of genetic susceptibility on the urinary excretion of 8-hydroxydeoxyguanosine of firefighters. Occup. Environ. Med. 57, 370375 (2000).

21 Sachse, C., Brockmuller, J., Bauer, S. \& Roots, I. Functional significance of a C>A polymorphism in intron 1 of the cytochrome P450 CYP1A2 gene tested with caffeine. Br. J. Clin. Pharmacol. 47, 445-449 (1999).

22 Goodman, M. T., McDuffie, K. \& Kolonel, L. N. Case-control study of ovarian cancer and polymorphisms in genes involved in catecholestrogen formation and metabolism. Cancer Epidemiol. Biomarkers Prev. 10, 209-216 (2001).

23 Lemos, M. C., Cabrita, F. J., Silva, H. A., Vivan, M., Plácido, F. \& Regateiro, F. J. Genetic polymorphism of CYP2D6, GSTM1 and NAT2 and susceptibility to haematological neoplasias. Carcinogenesis 20, 1225-1229 (1999).

24 Wong, N. A. C. S., Rae, F., Simpson, K. J., Murray, G. D., Harrison, D. J. Genetic polymorphisms of cytochrome p4502E1 and susceptibility to alcoholic liver disease and hepatocellular carcinoma in a white population: a study and literature review, including meta-analysis. J. Clin. Pathol. Mol. Pathol. 53, 88-93 (2000).

25 Spiecker, M., Darius, H., Hankeln, T., Soufi, M., Sattler, A. M., Schaefer, J. R. et al. Risk of coronary artery disease associated with polymorphism of the cytochrome P450 epoxygenase CYP2J2. Circulation 110, 2132-2136 (2004).

26 van Schaik, R. H., de Wildt, S. N., van Iperen, N. M., Uitterlinden, A. G., van den Anker, J. N. \& Lindemans, J. CYP3A4-V polymorphism detection by PCR-restriction fragment length polymorphism analysis and its allelic frequency among 199 Dutch Caucasians. Clin. Chem. 46, 1834-1836 (2000).

27 Smith, C. A. D. \& Harrison, D. J. Association between polymorphism in gene for microsomal epoxide hydrolase and susceptibility to emphysema. Lancet 350, 630-633 (1997).

28 Hassett, C., Aicher, L., Sidhu, J. S. \& Omiecinski, C. J. Human microsomal epoxide hydrolase: genetic polymorphism and functional expression in vitro of amino acid variants. Hum. Mol. Genet. 3, 421-428 (1994).

29 Sandberg, M., Hassett, C., Adman, E. T., Meijer, J. \& Omiecinski, C. J. Identification and functional characterization of human soluble epoxide hydrolase. J. Biol. Chem. $275,28873-28881$ (2000).
30 Ombres, D., Pannitteri, G., Montali, A., Candeloro, A., Seccareccia, F., Campagna, F. et al. The Gln-Arg192 polymorphism of human paraoxonase gene is not associated with coronary artery disease in Italian patients. Arterioscler. Thromb. Vasc. Biol. 18, $1611-1616$ (1998)

31 Sanghera, D. K., Aston, C. E., Saha, N. \& Kamboh, M. I. DNA polymorphisms in two paraoxonase gene (PON1 and PON2) are associated with the risk of coronary heart disease. Am. J. Hum. Genet. 62, 36-44 (1998).

32 Abdel-Rahman, S., El-Zein, R. A., Anwar, W. A. \& Au, W. W. A multiplex PCR procedure for polymorphic analysis of GSTM1 and GSTT1 genes in population studies. Cancer Lett. 107, 229-233 (1996).

33 Welfare, M., Adeokun, A. M., Bassendine, M. F. \& Daly, A. K. Polymorphisms in GSTP1, GSTM1, and GSTT1 and susceptibility to colorectal cancer. Cancer Epidemiol. Biomarkers Prev. 8, 289-292 (1999).

34 Hickman, D., Risch, A., Camilleri, J. P. \& Sim, E. Genotyping human polymorphic arylamine $\mathrm{N}$-acetyltransferase: identification of new slow allotypic variants. Pharmacogenetics 2, 217-226 (1992).

35 Zheng, W., Xie, D., Cerhan, J. R., Sellers, T. A., Wen, W. \& Folsom, A. R. Sulfotransferase $1 \mathrm{~A} 1$ polymorphism, endogenous estrogen exposure, well-done meat intake, and breast cancer risk. Cancer Epidemiol. Biomarkers Prev. 10, 89-94 (2001).

36 Lampe, J. W., Bigler, J., Horner, N. K \& Potter, J. D. UDP-glucuronosyltransferase (UGT1A1*28 and UGT1A6*2) polymorphisms in Caucasians and Asians: relationships to serum bilirubin concentrations. Pharmacogenetics 9, 341-349 (1999).

37 Jamroziak, K., Balcerczak, E., Młynarski, W., Mirowski, M. \& Robak, T. Distribution of allelic variants of functional C3435T polymorphism of drug transporter MDR1 gene in a sample of Polish population. Pol. J. Pharmacol. 54, 495-500 (2002).

38 Ritchie, M. D. \& Motsinger, A. A. Multifactor dimensionality reduction for detecting gene-gene and gene-environment interactions in pharmacogenomics studies. Pharmacogenomics 6, 823-834 (2005).

39 Motsinger, A. A. \& Ritchie, M. D. Multifactor dimensionality reduction: an analysis strategy for modelling and detecting gene-gene interactions in human genetics and pharmacogenomics studies. Hum. Genomics 2, 318-328 (2006).

40 Moore, J. H. Computational analysis of gene-gene interactions using multifactor dimensionality reduction. Expert Rev. Mol. Diagn. 4, 795-803 (2004).

41 Moore, J. H., Gilbert, J. C., Tsai, C. T., Chiang, F. T., Holden, T. \& Barney, N. et al. A flexible computational framework for detecting, characterizing, and interpreting statistical patterns of epistasis in genetic studies of human disease susceptibility. J. Theor. Biol. 241, 252-261 (2006).

42 Hahn, L. W., Ritchie, M. D. \& Moore, J. H. Multifactor dimensionality reduction software for detecting gene-gene and gene-environment interactions. Bioinformatics 19, 376-382 (2003).

43 Polonikov, A. V., Ivanov, V. P., Solodilova, M. A., Khoroshaya, I. V., Kozhuhov, M. A. \& Panfilov, V. I. Promoter polymorphism G-50T of a human CYP2J2 epoxygenase gene is associated with common susceptibility to asthma. Chest 132, 120-126 (2007).

44 Hill, W. G. Estimation of linkage disequilibrium in randomly mating populations. Heredity 33, 229-239 (1974).

45 Vogel, F. \& Motulsky, A. G. Human Genetics-Problems and Approaches 3rd edn (Springer, New York, 1997).

46 Lewontin, R. C. The Genetic Basis of Evolutionary Change (Columbia University Press, New York, 1974).

47 Jorde, L. B. Linkage disequilibrium as a gene mapping tool. Am. J. Hum. Genet. 56, 11-14 (1995).

48 Hedrick, P. W., Jain, S. \& Holden, L. Multilocus systems in evolution. Evol. Biol. 11, 101-182 (1978).

49 Hines, R. N., Koukouritaki, S. B., Poch, M. T. \& Stephens, M. C. Regulatory polymorphisms and their contribution to interindividual differences in the expression of enzymes influencing drug and toxicant disposition. Drug Metab. Rev. 40, 263-301 (2008).

50 Ding, X. \& Kaminsky, L. S. Human extrahepatic cytochromes P450: function in xenobiotic metabolism and tissue-selective chemical toxicity in the respiratory and gastrointestinal tracts. Annu. Rev. Pharmacol. Toxicol. 43, 149-173 (2003).

51 Sanghera, D. K., Aston, C. E., Saha, N. \& Kamboh, M. I. DNA polymorphisms in two paraoxonase gene (PON1 and PON2) are associated with the risk of coronary heart disease. Am. J. Hum. Genet. 62, 36-44 (1998).

52 Hayes, J. D., Flanagan, J. U. \& Jowsey, I. R. Glutathione transferases. Annu. Rev. Pharmacol. Toxicol. 45, 51-88 (2005).

53 Takizawa, H. S., Okazaki, A. H., Kohyama, T., Sugawara, I., Saito, Y., Ohtoshi, T. et al. Diesel exhaust particles up-regulate eotaxin gene expression in human bronchial epithelial cells via nuclear factor-kB-dependent pathway. Am. J. Physiol. 284, 1055-1062 (2003).

54 Ried, M. \& Diaz-Sanchez, D. Biology of diesel exhaust effects on respiratory function. J. Allergy Clin. Immunol. 115, 221-228 (2005).

55 Vogel, C. F., Sciullo, E., Wong, P., Kuzmicky, P., Kado, N. \& Matsumura, F. Induction of proinflammatory cytokines and C-reactive protein in human macrophage cell line U937 exposed to air pollution particulates. Environ. Health Perspect. 113, 1536-1541 (2005).

56 Saxon, A. \& Diaz-Sanchez, D. Air pollution and allergy. You are what you breathe. Nat. Immunol. 6, 223-226 (2005).

$57 \mathrm{Li}, \mathrm{N} ., \mathrm{Hao}, \mathrm{M}$., Phalen, R. F. \& Hinds, W. C. Nel AParticulate air pollutants asthmaA paradigm for the role of oxidative stress in PM-induced adverse health effects. Clin Immunol 109, 250-265 (2003). 